\title{
Biofilm Formation in a Permanent Tracheal Stent Implanted for Twenty- Five Years
}

\author{
Macé M. Schuurmans ${ }^{a} \quad$ Miguel Palheiros Marques $^{b} \quad$ Lutz Freitag $^{a}$ \\ Annelies S. Zinkernagel ${ }^{b}$ Yvonne Achermann ${ }^{b}$ \\ Divisions of a Pulmonology and ${ }^{b}$ Infectious Diseases and Hospital Epidemiology, University Hospital Zurich, \\ Zurich, Switzerland
}

At the age of 3 , our patient required a tracheostomy (metal cannula) after a tracheal injury following accidental aspiration of sulfuric acid, leading to central airway stenosis. At the age of 16, recurrent pulmonary infections led to the insertion of a tracheal silicone stent (Montgomery T-tube). Despite daily doses of inhaled antibiotics (colistin and tobramycin), airway clearance suctioning, and intermittent systemic antibiotic treatments to prevent and treat pulmonary infections, severe bronchiectasis with lung function decline occurred (FEV1, 1.37 liter; $35 \%$ predicted), and the patient was referred for lung transplant evaluation. To decrease the frequency of pulmonary infections, the stent was finally replaced at the age of 42 after the patient had refused replacement sev-
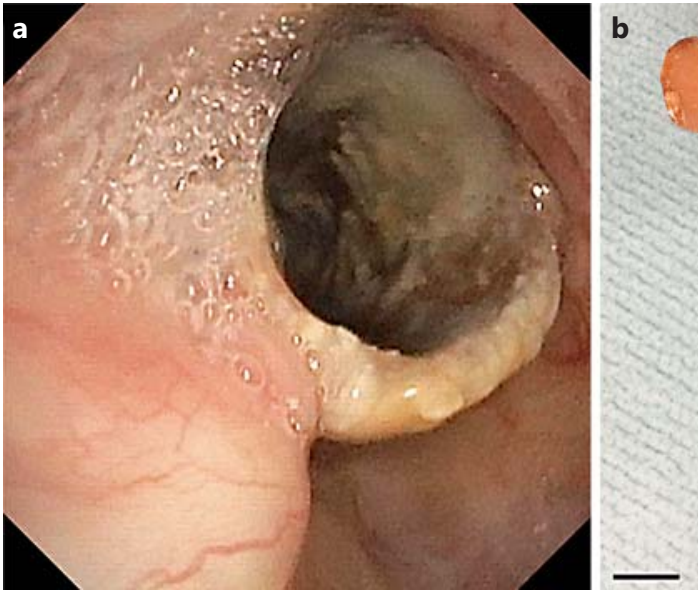

Fig. 1. a Endoscopic view of the proximal stent end in the subglottic region. b Macroscopic overview of the explanted Montgomery T-tube stent 25 years after insertion for tracheal stenosis in a teenager. $\mathbf{c}$ Visualization of a polymicrobial biofilm on the inner surface of the stent by using a Zeiss Supra 55VP field emission scanning electron microscope (Center for Microscopy and Image Analysis, University of Zurich, Zurich, Switzerland). For imaging, a piece of the stent was cut out (inset in b; scale bar: $1 \mathrm{~cm}$ ), showing a thick biomass (c; scale bar: $100 \mu \mathrm{m}$ ) and different shapes of bacteria, indicating a polymicrobial infection (inset in c; scale bar: $2 \mu \mathrm{m}$ ).

\section{KARGER 125}

(C) 2015 S. Karger AG, Basel

0025-7931/15/0904-0327\$39.50/0

E-Mail karger@karger.com

www.karger.com/res
Macé M. Schuurmans, MD, FCCP 
eral times. The removed stent was intact but discolored and covered by a biofilm (fig. 1a, b) [1]. Stenotrophomonas maltophilia (moderate growth), Corynebacterium amycolatum (strong growth), Candida albicans (moderate growth), coagulase-negative staphylococci and anaerobes (in broth) were cultured from the stent. Both Stenotrophomonas maltophilia and Corynebacterium amycolatum had been previously isolated during bronchoscopy examination. Scanning electron microscopy (SEM) of the explanted stent showed rod-shaped bacteria embedded in a thick biofilm structure (fig. 1c), compatible with the isolated bacteria (fig. 1c, inset).

For short-term use of endotracheal tubes, biofilm formation contributes to ventilator-associated pneumonia and recalcitrance of antibiotic treatment $[2,3]$. Silvercoating tubes may be a promising strategy to reduce the number of adhering bacteria [4]. There are no reports on long-term stenting exceeding more than 1 decade or, as in our patient, for 25 years. The isolation of different bac- teria on the inside of the stent with visualization by scanning electron microscopy suggests biofilm formation as the source of recurrent tracheobronchial infections.

References

1 Dutau H, Vandemoortele T, Laroumagne S, Astoul P: A tanned stent. Respiration 2013;85: 436-437.

-2 Prasanna Kumar S, Ravikumar A, Senthil K, Somu L, Nazrin MI: Role of Montgomery Ttube stent for laryngotracheal stenosis. Auris Nasus Larynx 2014;41:195-200.

3 Vandecandelaere I, Coenye T: Microbial composition and antibiotic resistance of biofilms recovered from endotracheal tubes of mechanically ventilated patients. Adv Exp Med Biol 2015;830:137-155.

4 Rello J, Afessa B, Anzueto A, Arroliga AC, Olson ME, Restrepo MI, Talsma SS, Bracken RL, Kollef MH: Activity of a silver-coated endotracheal tube in preclinical models of ventilatorassociated pneumonia and a study after extubation. Crit Care Med 2010;38:1135-1140. 